\title{
Malignant Cervical Neoplasm
}

National Cancer Institute

\section{Source}

National Cancer Institute. Malignant Cervical Neoplasm. NCI Thesaurus. Code C9311.

A primary or metastatic malignant neoplasm involving the cervix. 